\title{
ASSISTÊNCIA AO ADOLESCENTE EM UM SERVIÇO TERCIÁRIO: ACESSO, ACOLHIMENTO E SATISFAÇÃO NA PRODUÇÃO DO CUIDADO
}

\author{
Maria Veraci Oliveira Queiroz ${ }^{1}$ Edivânia Maria Vasconcelos Ribeiro², Viviane Peixoto dos Santos Pennafort ${ }^{3}$
}

\begin{abstract}
${ }^{1}$ Doutora em Enfermagem. Docente do Curso de Graduação em Enfermagem e do Curso de Mestrado Acadêmico em Cuidados Clínicos em Saúde da Universidade Estadual do Ceará (UECE). Ceará, Brasil. E- mail: veracioq@hotmail.com

${ }^{2}$ Enfermeira do Centro de Saúde Dr. Lúcio Alcântara. Ceará, Brasil. E-mail: edivania_vasconcelos@yahoo.com.br

${ }^{3}$ Mestre em Cuidados Clínicos em Saúde. Professora substituta da UECE. Ceará, Brasil. E-mail: vivipspf@yahoo.com.br
\end{abstract}

RESUMO: Estudo exploratório-descritivo com abordagem qualitativa que objetivou identificar as formas de acesso e acolhimento de adolescentes em um serviço de saúde, descrever a satisfação com o cuidado recebido e as relações estabelecidas com os profissionais. Realizado no Hospital Geral de Fortaleza, participaram sete adolescentes internados na Unidade Pediátrica por meio de entrevista semiestruturada. As entrevistas foram submetidas à análise de conteúdo. Os adolescentes demonstraram conhecimentos sobre as condições de saúde e tratamento. Perceberam condições satisfatórias de acesso e acolhimento com restrições à porta de entrada. Destacaram aspectos positivos da relação, da comunicação e da resolubilidade dos problemas na unidade de internação. A escuta e o acolhimento são as principais ações para a satisfação durante os cuidados. Há, portanto, necessidade de um agir pautado nos dispositivos da integralidade por todos os membros da equipe de saúde e em todos os espaços na produção do cuidado aos adolescentes.

DESCRITORES: Adolescente. Acesso aos serviços de saúde. Acolhimento. Satisfação do paciente.

\section{ADOLESCENT ASSISTANCE IN A TERTIARY SERVICE: ACCESS, EMBRACEMENT, AND SATISFACTION IN CARE PRODUCTION}

\begin{abstract}
The exploratory-descriptive qualitative study aimed to identify the access and embracement forms presented by the service, according to the adolescents' perception, describe the satisfaction of these subjects and the relationships established with the professionals in the received care. It was carried out at the General Hospital of Fortaleza, Ceara, Brazil, seven adolescents interned in the Pediatric Unit participated of the study through a semi-structured interview. The interviews were submitted to content analysis. The adolescents demonstrated knowledge concerning the health care and treatment conditions. They noticed satisfactory access and embracement conditions with restrictions concerning the entrance door. They highlighted positive aspects of the relationships, the communication, and the resolvability of the inpatient unit problems. Listening and embracement were the main actions towards satisfaction during care. There is, however, the need for actions based on devices for the integrality of all the health team members and in all the adolescent care production areas.
\end{abstract}

DESCRIPTORS: Adolescent. Health services accessibility. User embracement. Patient satisfaction.

\section{LA ASISTENCIA A LOS ADOLESCENTES EN UN SERVICIO DE SALUD: ACCESO, ACOGIDA Y SATISFACCIÓN EN LA PRODUCCIÓN DE LA ATENCIÓN}

RESUMEN: Es un estudio exploratorio, descriptivo, con enfoque cualitativo, que buscó identificar las maneras de acceso y de acogida a los adolescentes en un servicio de salud, para describir la satisfacción con la atención recibida y las relaciones con los profesionales. La investigación se llevó a cabo a través de entrevistas semiestructuradas con siete adolescentes internados en la unidad pediátrica del Hospital General de Fortaleza, Ceará, Brasil. Las entrevistas se analizaron por medio del analisis de contenido. Los adolescentes demostraron conocimientos sobre las condiciones de salud y el tratamiento. Percibieron condiciones satisfactorias de acceso y acogida, con restricciones a la puerta de entrada. Destacaron los aspectos positivos de la relación, de la comunicación y de la resolución de los problemas en la unidad de hospitalización. Escuchar y acoger fueron las principales acciones señaladas por los adolescentes para la satisfacción durante la atención. Por lo tanto, existe la necesidad de acciones basadas en los dispositivos de la integralidad de todos los miembros del equipo de salud y en todas los lugares en los que se ofrece la atención a los adolescentes.

DESCRIPTORES: Adolescente. Accesibilidad a los servicios de salud. Acogimiento. Satisfacción del paciente. 


\section{INTRODUÇÃO}

Concepções e práticas no cuidado ao adolescente são constituídas com base em necessidades detectadas pelos agentes produtores de saúde. A atenção ao adolescente configura-se como espaço essencial nos âmbitos da assistência e da formação acadêmica, em ambientes de produção de cuidados, que buscam transformações focalizadas nos aspectos da humanização e da formação do sujeito e de sua cidadania. Nesse sentido, as ações voltadas à saúde do adolescente devem ter consonância com as necessidades e demandas evidenciadas no campo de prática.

A assistência à criança e ao adolescente é alvo de maior atenção desde a configuração da Lei $N^{\circ}$ 8.069 que dispõe sobre o Estatuto da Criança e do Adolescente (ECA) e dá outras providências. Esta Lei resultou de uma luta ampla dos setores sociais organizados que buscaram criar um novo espaço político e jurídico para a criança e o adolescente brasileiro, e constitui uma legislação que visa ao desenvolvimento integral destes sujeitos. ${ }^{1}$

Para os efeitos desta Lei, considera-se criança a pessoa até 12 anos de idade incompletos, e adolescente aquela entre 12 e 18 anos. ${ }^{2}$ Segundo a Organização Mundial de Saúde, a adolescência é a etapa da vida que compreende a faixa etária entre 10 e 19 anos, considerando a juventude dos 15 aos 24 anos. Esses conceitos comportam desdobramentos, identificando-se adolescentes jovens de 15 a 19 anos e adultos jovens de 20 a 24 anos. ${ }^{3}$

Na área de saúde, em fevereiro de 2004, foi realizada, em Brasília, a Oficina de Construção da Política Nacional de Atenção à Saúde de Adolescentes e Jovens, sob a promoção e a liderança da Área de Saúde do Adolescente e do Jovem (ASAJ). Esta política tem o "compromisso de incorporar a atenção à saúde deste grupo populacional à estrutura e mecanismos de gestão, à rede de atenção do Sistema Único de Saúde (SUS) e às ações e rotinas do SUS em todos seus níveis". 4:1

A enfermagem, recentemente, tem buscado referenciais teóricos e metodológicos que fundamentem novas proposições do cuidado junto a adolescentes. Embora já se possa dispor de conhecimentos e práticas importantes, ainda carece de aprofundamentos, discussão e divulgação ampliada, abrangendo a capacitação dos seus trabalhadores, nos mais diversos contextos assistenciais ou campos de trabalho que incluem o adolescente.

Percebe-se um despreparo dos serviços de saúde em relação às práticas de cuidado com adolescentes, de forma a atender as peculiaridades e complexidades das suas necessidades, faltando espaços e suporte apropriados às suas demandas, seja no campo da orientação, proteção ou recuperação da saúde. ${ }^{5}$

Nessa perspectiva, a integralidade é um ponto central das discussões que integram vários conceitos e práticas no campo da produção de cuidados. A integralidade, entendida como prática social e como um princípio universal da política de saúde do Estado brasileiro, oferece o exercício da soma de saberes e experiências, além de trilhar caminhos possíveis para formar com a responsabilidade coletiva algo melhor no campo da saúde. ${ }^{6}$

São muitos os sentidos da integralidade, incluindo o direito universal ao atendimento das necessidades de saúde do usuário de forma digna e acolhedora, oferecendo respostas abrangentes e adequadas para a resolutividade das ações no sistema. ${ }^{7}$ Logo, a integralidade na atenção à saúde orienta políticas e ações programáticas para responder às demandas e necessidades da população no acesso à rede de cuidados em saúde, considerando a complexidade e as especificidades de variadas abordagens do processo saúde-doença e nas distintas dimensões - biológica, cultural e social - que envolvem o indivíduo. ${ }^{8}$

Ao inserir esta perspectiva na assistência ao adolescente em ambiente hospitalar, considera-se importante refletir sobre a produção do cuidado a este grupo para que se possa definir o diagnóstico da situação atual e orientar possíveis caminhos que garantam os processos de implementação da política de saúde com eficiência e qualidade. Sabe-se que, apesar das modificações favoráveis no que se refere aos serviços de atenção à criança e ao adolescente, muitos indicadores sensíveis sobre o estado de saúde desta população e as responsabilidades dos serviços ainda se mostram incapazes de atendê-los satisfatoriamente.

A proposição de debater sobre modos e instrumentais de trabalho é aqui compreendida como o cuidado capaz de atender necessidades e demandas do adolescente pelos agentes produtores do trabalho que, em negociação com os usuários, desenvolvem encontros que facilitam ou não o acesso, o acolhimento e a própria satisfação. Daí decorre uma característica fundamental desta pesquisa: conhecer tal realidade com suporte na visão dos adolescentes que detêm a experiência vivenciada no ambiente hospitalar. Promover a discussão desses dispositivos incorporados no princípio da integralidade torna-se essencial para que haja possibilidade 
de resignificação do trabalho da enfermagem e de outros profissionais junto aos adolescentes, acreditando no potencial de recriação e apropriação de instrumentos de ação capazes de mudar a realidade, na qual pressupõe-se a constituição de laços de solidariedade e compromisso de respeito como sujeitos de direitos e autonomia.

Para efetivar a pesquisa, apoiou-se no seguinte objetivo: identificar as formas de acesso e acolhimento de adolescentes em um serviço de saúde, descrever a satisfação com o cuidado recebido e as relações estabelecidas com os profissionais.

\section{METODOLOGIA}

Trata-se de um estudo exploratório-descritivo com abordagem qualitativa que teve como pressuposto a experiência humana com sentidos e significados que derivam dos contextos da vida. Em vez de simplesmente aceitar os contextos e explicações utilizados na vida diária, a pesquisa qualitativa faz perguntas fundamentais e investiga a natureza dos fenômenos sociais. ${ }^{9}$

A pesquisa foi desenvolvida no Hospital Geral de Fortaleza (HGF), um hospital de referência na atenção terciária do SUS situado em Fortaleza$\mathrm{CE}$, que funciona com acesso por procura direta ou por encaminhamento de outros serviços médicos da Capital e outras cidades do Estado. A instituição encontrava-se em reforma, e durante o período da pesquisa, março a abril de 2008, dispunha de 337 leitos, distribuídos em diversas áreas da assistência, incluindo a atenção à criança e ao adolescente em ambulatórios especializados e na unidade de internação, com 36 leitos, sendo apenas uma enfermaria com cinco leitos destinados à hebiatria. * A unidade de saúde é certificada como hospital de ensino com atividades assistenciais, pesquisa e ensino nas diversas áreas da saúde e colaboradores da área de recursos humanos dos cursos de graduação, especialização, internato de Medicina e de Enfermagem e residência médica.

Participaram da pesquisa sete adolescentes que estavam internados no setor de pediatria/ hebiatria, e uma mãe voluntária que expressou a necessidade de relatar a experiência vivida com a filha. A escolha foi intencional, seguindo aos critérios de inclusão: adolescentes entre $12 \mathrm{e}$ 18 anos (conforme classificação do ECA), com possibilidades mentais de expressar opiniões e que aceitaram participar do estudo com anuência dos pais ou responsáveis. Para determinar o número de sujeitos, obedeceram-se aos critérios de saturação teórica, cujo fim da coleta ocorre quando outras observações não trazem nenhum conhecimento adicional. ${ }^{10}$

Para a coleta de dados, foi elaborado um roteiro de entrevista semiestruturada com perguntas envolvendo acesso, acolhimento, satisfação, além das condições relacionais que perpassaram as questões principais do estudo. As entrevistas foram gravadas com a permissão e assinatura do Termo de Consentimento Livre e Esclarecido (TCLE), pelos sujeitos da pesquisa e seus responsáveis legais, e em seguida, transcritas pelas pesquisadoras, mantendo na íntegra o conteúdo das falas. Para análise dos dados, adotaram-se os passos operacionais que se refere à análise de conteúdo: ordenação, classificação e análise final dos dados. ${ }^{11}$ Primeiramente, organizou-se o material empírico, com transcrição dos dados, agrupando os que diziam respeito a temas afins, obtidos nas entrevistas, para possibilitar a contraposição entre a perspectiva dos sujeitos e a observação do concreto do trabalho. Em seguida, procedeu-se à leitura exaustiva dos discursos, para apreender as ideias centrais e convergências nos diferentes discursos dos participantes, os quais originaram temas centrais que foram agrupados nas seguintes categorias temáticas: conhecimentos sobre o problema de saúde; dificuldades e facilidades de acesso ao serviço, acolhimento no serviço de saúde e satisfação dos adolescentes nas interações e na produção do cuidado.

O projeto da investigação foi apreciado, tendo sido lavrado parecer favorável à sua realização pelo Comitê de Ética em Pesquisa, da instituição locus da pesquisa, com o parecer de $\mathrm{n}^{\circ} 101006 / 07$. Todos os passos da investigação seguiram a Resolução ${ }^{\circ}$ 196/96, do Conselho Nacional de Saúde, sobre os preceitos éticos de estudos com seres humanos. ${ }^{12}$

\section{RESULTADOS E DISCUSSÃO}

Os resultados das entrevistas com os adolescentes mostram que três eram do sexo feminino e quatro do sexo masculino. A idade dos entrevistados variou de 13 a 17 anos. Apenas um adolescente era procedente de outra cidade do Estado e os demais de Fortaleza. O tempo de permanência dos adolescentes nessa hospitalização foi de sete

\footnotetext{
* Hebiatria é o ramo da medicina voltado para o diagnóstico e o tratamento das doenças que ocorrem durante o período que se inicia na puberdade e termina com a cessão do crescimento somático.
} 
a trinta dias e todos estavam, durante a pesquisa, acompanhados de seus pais ou pessoa responsável naquele momento, autorizado pelos pais.

Foi inquirido junto a esses adolescentes como se conforma o acesso ao serviço de saúde e como eles foram acolhidos na instituição da pesquisa, apreendendo-se também a satisfação no momento em que recebiam os cuidados. Estes pontos fundamentais estão apresentados nas categorias temáticas expostas a seguir.

\section{Conhecimentos sobre o problema de saúde}

O entendimento sobre as condições peculiares ao internamento hospitalar dos adolescentes é representado pelas experiências dos próprios sujeitos, que revelam, objetivamente, os motivos principais da internação e as condições de hospitalização e de saúde em que eles se encontravam naquele dado momento. Assim, manifestaram os adolescentes:

Eu tenho diabete... a diabete é o sangue doce, tem que ter um tratamento, ai vai ter que tomar insulina, só que eu não sei falar da doença (E4).

Eu tenho febre reumática, dois sopros no coração. Eu vim com muitas dores nas juntas [...] (E7).

Os discursos evidenciam que os adolescentes detinham algum conhecimento a respeito da doença e, essencialmente, do motivo da internação, o que lhes permitiu saber sobre seu estado de saúde e possível tratamento. Com tais informações, infere-se que eles foram cientificados da situação de saúde em que se encontravam.

É importante considerar que o adolescente pode ser visto como sujeito de direitos e deveres, fazendo-se necessário provê-los de informações sobre seu estado de saúde, de maneira clara, objetiva, respeitosa, compreensível e adaptada à condição cultural. ${ }^{3}$ Os profissionais de saúde, ao cuidar do ser que necessita de seus conhecimentos e habilidades, devem exercitar a valorização primeira do lado humano, reunindo os valores e motivações fundamentais de cada indivíduo. Valorizar os sujeitos, a autonomia, a responsabilidade, a abertura, a ética, o entendimento intersubjetivo e a relação dialógica, é priorizar um cuidado voltado para as exigências e necessidades do cliente com compartilhamento, não somente de palavras, ideias e informações, mas de sentimentos, emoções e sensibilidade. ${ }^{13}$

\section{Dificuldades e facilidades de acesso ao serviço}

Ao serem questionados sobre o acesso, os adolescentes apresentam percepções diferentes.
Para alguns usuários, houve dificuldade no acesso em relação à disponibilidade do serviço, pois não apareceu resposta imediata às suas necessidades, mas um aprazamento demorado com custos à sua saúde. As queixas referem-se, principalmente, ao tempo de espera e às longas filas. Durante a entrevista com E4, sua mãe se manifestou e relatou sobre a experiência vivida.

O que eu achei difícil não foi nem a distância onde eu moro [...]. Nós chegamos aqui de manhã e ela foi atendida 5:30 da tarde. Ela tava muito doente e aí eu não gostei dessa parte de jeito nenhum. Eu comecei a chorar, o guarda teve pena de mim, foi ele que deixou a gente entrar. Ele faz a fila, coloca os idosos na frente... minha filha tava provocando, doente, desmaiando, eu implorei pra ele deixar eu entrar com ela. O problema é só a fila que a gente tem que enfrentar lá fora (Mãe de E4).

Quando eu vim em janeiro, ela [enfermeira] disse que tava muito cheio e que eu viesse em fevereiro. Foi ruim isso que eu tinha que ficar indo e voltando (E1).

Esses relatos sinalizam de fato a realidade enfrentada sobre o acesso dos usuários aos serviços. Mesmo em condições emergenciais, em se tratando de adolescentes, ainda acontece de forma reservada, despercebida, pois é uma fase da vida em que não há reconhecimento nem inclusão nas prioridades. Contudo, todo adolescente tem o direito de ser atendido na rede de saúde, assim como nos postos de saúde, nos ambulatórios, nas equipes de Saúde da Família e nos hospitais que fazem parte do SUS. ${ }^{14}$

Outro ponto de vista é o de que, no Brasil, os hospitais em geral, atuam de maneira desarticulada dos demais serviços, principalmente daqueles responsáveis pela atenção primária. Hoje, a ausência de uma rede de atenção primária resolutiva e de um sistema de saúde integrado pressiona os hospitais por meio de uma demanda excessiva em relação à sua capacidade de resposta, ensejando filas e mau atendimento. ${ }^{15}$

Vale ressaltar ainda, com base nos depoimentos, que a dificuldade de acesso deu-se na porta de entrada, lugar onde é realizada a "triagem" das pessoas que procuram o serviço hospitalar, sejam elas oriundas de uma demanda espontânea ou referenciada por outros serviços. Ela foi realizada, no entanto, por trabalhador não qualificado para tal atividade, mostrando uma prática burocrática, pouco acessível e nada resolutiva. Essa é uma dimensão importante a se considerar, uma vez que este passa a ser responsável por acolher e supostamente dar resposta aos problemas e às necessidades dos usuários. ${ }^{16}$ 
O acesso aos serviços é a primeira fase a ser ultrapassada pelo usuário quando está buscando satisfazer uma necessidade na área da saúde. ${ }^{17} \mathrm{O}$ acesso universal aos serviços de saúde, indispensável para garantir a equidade no atendimento, ainda que garantido constitucionalmente, não se concretiza para a maioria da população.

É bem verdade que a hospitalização é um caminho, por vezes longo, difícil e imprevisível na vida dos que dela necessitam e, até que o diagnóstico da doença seja definitivo, as pessoas vivenciam verdadeira peregrinação com a ida de um hospital a outro em busca de algum centro que explique e resolva seu problema. ${ }^{18}$ Tal realidade pode ser observada no seguinte relato: [...] me jogaram de um hospital para outro... eu fui para o Gonzaguinha do José Walter. Tava saindo muito sangue do meu nariz, não sabiam o que fazer comigo, iam mandar eu ir pra casa. Aí fui pra Caucaia... e ele me encaminhou para cá (E3).

O acesso está relacionado à oferta de serviços. O uso de serviços faz parte do conceito de acesso, mas não se explica apenas por ele. Fatores individuais predisponentes e contextuais também influenciam a condição de acesso. Nota-se uma tendência a ampliar a dimensão do conceito de acesso, "com deslocamento do seu eixo da entrada nos serviços (uso) para os resultados dos cuidados recebidos" ${ }^{19: 197}$ Neste caso, o acesso é analisado também pelo seu impacto na saúde, na resolutividade do problema de saúde que ensejou a procura e na adequação do cuidado produzido. Assim, ele será melhor apreciado nos modos específicos de encontros de usuários e trabalhadores no processo de trabalho.

Outros discursos dos adolescentes mostram posicionamentos diferentes, que negam a dificuldade em conseguir assistência no serviço. Eles referiram um atendimento rápido e resolutivo diante do seu problema. Os que não perceberam quaisquer dificuldades de acesso vieram encaminhados de outros serviços de saúde do sistema secundário, portanto, tinham a vaga garantida.

Eu não tive dificuldade não. Mesmo morando longe daqui, eu consegui logo a vaga. Foi só chegar que deu certo, eu vim encaminhado (E2).

Aqui foi muito rápido, a gente chegou, a mulher pediu nossa ficha, aí subimos direto para cá. Eu não tive dificuldade nenhuma (E5).

Certamente, a facilidade relatada decorreu da integração da rede de serviços que efetivamente funcionou, havendo, deste modo, a comunicação entre a atenção secundária e terciária. O sistema de encaminhamento de usuários pelas centrais de internação foi criado como ferramenta para regular o acesso às internações hospitalares, para se obter equidade e qualidade do cuidado à saúde, fazendo a ponte entre as demandas e a oferta disponível para a internação. ${ }^{20}$

\section{Acolhimento no serviço de saúde}

$\mathrm{O}$ acolhimento consiste em um "conjunto de ações que fazem com que o indivíduo se sinta bem recebido pelo serviço em todos os locais e momentos. Esse processo, fundamental para a constituição de vínculos e compromissos, favorece o encaminhamento adequado do cliente" ${ }^{21: 16}$ É uma ferramenta que permite o acesso universal aos serviços, favorece a resolutividade e a qualidade da assistência.

A posição acolhedora do profissional de saúde ante o usuário, evidenciada principalmente na unidade de internação, mostrou, na maioria dos relatos, a satisfação do adolescente em momentos específicos da produção do cuidado. Para os adolescentes, a atitude receptiva, a escuta e a resolubilidade foram importantes.

Eu fui muito bem recebido aqui no hospital, todos foram legais comigo, me trataram bem e deu tudo certo, a minha cirurgia já ta marcada pra segunda-feira (E2).

Quando eu cheguei aqui, as enfermeiras vieram ver com eu tava me sentindo, me colocaram no leito. O médico veio me ver logo. Foi muito bom. Fui logo atendido (E7).

Os discursos corroboram a ideia ampliada de acolhimento, ou seja, uma eficiente estratégia para operacionalizar as principais diretrizes do SUS: universalidade, integridade e equidade. Implica incorporar essa diretriz [acolhimento] na constituição de políticas de saúde, na rede básica municipal de saúde e no sistema hospitalar, implantando serviços de apoio terapêutico e social, formulando e fortalecendo espaços de controle social.

Os discursos também mostram algumas divergências destacadas em relatos de dois adolescentes quanto ao comportamento dos profissionais.

Teve só uma vez que eu vi que fui maltratada, a mulher foi com ignorância, era a enfermeira lá embaixo [emergência] (E1).

Lá fora [emergência] foi péssimo o atendimento, eu não gostei. O médico pediu os exames, quando eu vim no outro dia o médico ele nem olhou pra mim (E4).

Apesar das evidências positivas de um bom acolhimento, algumas experiências mostram a 
ausência dessa atitude na porta de entrada do serviço, espaço no qual ocorre o reconhecimento das necessidades dos usuários por meio da investigação, elaboração e das negociações que serão atendidas e que somente poderão se concretizar de maneira satisfatória quando associadas ao bom acolhimento. $^{22}$

O acolhimento deve ser de responsabilidade de toda a equipe de saúde, pois somente dessa maneira é possível atender de fato as demandas e necessidades dos sujeitos reais do trabalho em saúde. No discurso a seguir, uma adolescente ressalta a necessidade de haver um bom acolhimento por parte dos profissionais que integram o serviço de saúde ${ }^{23}$

Fui bem recebida por todos. Ainda bem, porque você já tá doente num hospital e não lhe tratarem bem é horrivel (E6).

Percebe-se no discurso anterior o alívio da adolescente pelo atendimento eficaz e ao mesmo tempo sua angústia com o fato de um indivíduo estar hospitalizado e não receber uma atenção adequada, considerando-se, nesta perspectiva, o acolhimento e outros fatores que permeiam a interação usuário-profissional.

Comportamentos de acolhimento são essenciais para compreender as necessidades de saúde do adolescente em condição de doença e hospitalização, pois expressam, além de uma condição biológica, outras necessidades psicossociais que se manifestam nos receios, temores e desejos. Nesse sentido, torna-se importante compreender os aspectos que permeiam a adolescência, considerando a multidimensionalidade de transformações que acontecem nesta fase. Há necessidade de compreensão e apoio ao enfrentamento da situação para que atinja uma condição menos estressante durante as intervenções terapêuticas. Para o adolescente, o hospital é o mundo estranho, que foge à compreensão dos jovens. É o mundo da terminologia complexa, dos aparelhos, em que sofrem, compartilham a dor com os outros. É no hospital, também, que o reconhecem e se reconhece como doente, no qual se sente preso à realidade da doença. ${ }^{24}$

Ao apreender os discursos dos adolescentes, observaram-se as relações que se estabelecem entre os usuários e os profissionais de saúde, principais formadores de vínculo. Entende-se que o vínculo confere segurança aos usuários, permitindo que os trabalhadores do serviço os conheçam para melhor estabelecer as prioridades na atenção à sua saúde. ${ }^{17}$ Nesse movimento, a criação de vínculos implica relações próximas, com sensibilidade à situação do outro, permitindo a constituição de um processo de transferência entre o usuário e o trabalhador de saúde que possa servir à constituição da autonomia. ${ }^{8}$

Ao questionar os adolescentes sobre quem eram os profissionais responsáveis pelo acompanhamento e os cuidados na enfermaria, responderam:

São dois médicos (X e Y)... as enfermeiras, assistente social, a nutricionista (E4).

São muitos. Eu não sei nem o nome deles. Eles conversam comigo, tiram brincadeiras, mas como são muitos, eu não sei nem o nome (E6).

Estes discursos mostram a diversidade de profissionais envolvidos na assistência, no entanto, o responsável pelo seguimento e o cuidado direto não foi identificado pelos adolescentes. Diante destas repostas, cogita-se: será que a relação estabelecida entre usuários e profissionais no ambiente hospitalar proporciona esse vínculo? A participação ativa do sujeito no cuidado está presente nessa relação? Estes são alguns pontos relevantes na produção do cuidado, que podem gerar autonomia e emancipação dos sujeitos. Vale ressaltar que, em hospitais de ensino, há um contingente de estudantes que assistem o paciente, alguns com responsabilidades e supervisão do docente/preceptor. Isto pode acarretar prejuízos para se manter vínculo, uma vez que são muitos os que cuidam, porém não são todos que têm a permanência efetiva dentro do serviço.

O uso dos hospitais públicos como locais de estágio para as universidades que possuem cursos na área da saúde traz grande rotatividade de alunos. "[...] o doente é assistido pelos profissionais da instituição, geralmente em número significativo (médicos, enfermeiros e auxiliares de enfermagem, fisioterapeutas, nutricionista, etc.) e acadêmico ou residente de diversos cursos da área da saúde. Conforme o curso, o tempo de permanência destes estagiários pode ser de dias ou até de meses, havendo, portanto, uma contínua rotatividade e entrada de novos alunos". 25:47

O cuidado em saúde na prática hospitalar, recebido/vivido pelo paciente, resulta de um grande número de pequenos cuidados que vão se completando entre os vários cuidadores que circulam e produzem a vida do hospital. Tornase uma complexa trama de atos, procedimentos, fluxos, rotinas e saberes, num processo dialético de complementação, mas também da disputa. ${ }^{26}$ 
Nota-se ainda que é preciso fortalecer as tecnologias leves, operando como " [...] tecnologias de relações, de encontros de subjetividades, para além dos saberes tecnológicos estruturados". 27:121 Nesse sentido, salienta-se que, mesmo diante das dificuldades enfrentadas pelos adolescentes e sua família em obter acesso e soluções mais imediatas, houve situações compensadoras por meio das interações que se estabeleceram com os trabalhadores de saúde. Os discursos evidenciaram muitas relações positivas que sinalizaram a satisfação, de certo modo, dos usuários.

\section{Satisfação dos adolescentes na produção do cuidado}

A satisfação do usuário focaliza as distintas dimensões que envolvem o cuidado à saúde, desde a acessibilidade, relação profissional-paciente, passando pelas condições estruturais. Dessa forma, esses aspectos avaliam o quanto os serviços de saúde atendem às expectativas dos usuários.

Nos discursos dos adolescentes, evidenciase uma satisfação com o serviço, principalmente com a unidade em que estavam internados. A satisfação dos usuários aparece relacionada aos aspectos humanitários, à comunicação com os profissionais, enfim, às relações estabelecidas na produção dos cuidados.

Aqui sou atendida muito bem, cuidam bem de mim. Quando botavam a medicação perguntavam se tava doendo meu braço (E1).

Alguns me explicam quando vem furar meu dedo, falam da insulina e como aplicar. Eu acho importante isso porque em casa eu vou ter que fazer isso sozinha (E4).

Os adolescentes reconheceram que o cuidado foi diferenciado, registraram a presença e a preocupação da equipe de saúde na orientação dos cuidados realizados. Assim, a percepção dos usuários sobre a satisfação está associada ao tratamento digno, respeitoso, e com qualidade, os quais permitem iluminar as relações, de modo que saberes e práticas interagem continuamente. ${ }^{28}$ Continua a ser importante curar doenças, mas sem esquecer de que mais importante ainda é curar o doente; e não somente curá-lo, mas também cuidá-lo. É a pessoa doente que deve ser o principal foco de atenção, e não a sua enfermidade. Ainda quando a cura não é mais possível, quando a ciência se julga incapaz de resolver o problema trazido pela doença, continua-se diante do doente, na sua dignidade, fragilidade e necessidade de ser amparado, cuidado e amado. ${ }^{29}$
Embora a satisfação com o serviço tenha sido manifestada, é fácil perceber nos relatos a angústia e a ansiedade dos adolescentes por estarem internados e longe da vida cotidiana anterior ao adoecimento. Pode-se compreender tal fato, especialmente se considerar os adolescentes seres que têm necessidades e características singulares.

Aqui é bom, só é ruim o tempo que eu já tô aqui. Vai fazer um mês e to doido pra ir pra casa, mas só posso ir depois da cirurgia, quando eu ficar bom (E3).

Eu tô com muita saudade de casa. Até chorar eu chorei. E eu ainda tô triste por causa da visita que eu tava esperando não veio ninguém (E6).

$\mathrm{O}$ ambiente hospitalar, com suas características, estrutura física, rotinas para o adequado andamento do trabalho diário, interfere na rotina diária domiciliar de crianças e adolescentes. Dessa forma, as atividades como dormir, comer e higienizar-se são alteradas, assim como o contato do paciente com sua família, amigos e outros inseridos em sua rede de relações já não é mais o mesmo depois da hospitalização. ${ }^{25}$ Além disso, esta enseja insegurança e uma peculiar ansiedade. O hospital é quase sempre um lugar de sofrimento e dor, de espera e angústia, quando não de desolação e desesperança. ${ }^{29}$

Diante da doença e hospitalização, há relatos que apontam estratégias e modos para minimizar a convivência que envolve o ser adolescente com o ser hospitalizado. Os adolescentes buscam meios para enfrentar de modo mais agradável a hospitalização.

Aqui tem as tias da escolinha [terapia ocupacional], às vezes eu participo, essa semana teve desenho, é bastante legal (E3).

[...] tem televisão, têm os brinquedos pra gente brincar (E5).

Observam-se nas falas as várias maneiras para humanizar estes espaços, tornando-os mais acolhedores. O setor de internação pediátrica oferece algumas possibilidades interativas, como a televisão, jogos, livros e um espaço amplo para momentos de prazer e descontração.

Os profissionais de saúde devem buscar compreender os elementos relevantes para elaboração do processo terapêutico do usuário, valorizando seu sofrimento, expectativas e temores, refletindo sobre os sentidos da integralidade, envolvendo ainda a prática do cuidado, do acolhimento e da humanização, instrumentos essenciais para que os profissionais e os serviços de saúde desenvolvam uma assistência integral. A integralidade da assistência 
é o alicerce para o alcance de melhor qualidade das ações e serviços voltados para a promoção da saúde, prevenção, recuperação e reabilitação. ${ }^{7}$

Para que o exercício da cidadania seja pleno, faz-se necessário que os adolescentes tenham condições democráticas de acesso a bens e serviços e possam reivindicar os seus direitos a uma atenção de qualidade, com um entendimento amplo de que saúde não resulta da ausência de doenças, mas de um conjunto de fatores que os levem à prática de um estilo de vida saudável. ${ }^{1}$ Dessa forma, a conjugação dos dispositivos que promovem a integralidade se sobrepõe ao contexto da satisfação do usuário. Todos remetem à discussão de modelos assistenciais a serem adotados nos serviços de saúde que fazem parte da reorganização dos serviços e da qualificação da assistência prestada de forma equânime e universal.

\section{CONSIDERAÇÕES FINAIS}

A aproximação com adolescentes hospitalizados e a escuta desses sujeitos foram elementos essenciais para o alcance do objetivo, permitindo a compreensão de questões envolvidas na constituição do SUS: acessibilidade, acolhimento, vínculo, participação, responsabilização, entre outros dispositivos da integralidade da atenção. Aspectos, certamente, relacionados à qualidade da assistência e à satisfação do cliente.

O diálogo entre usuários e profissionais de saúde, de certa forma, esteve presente, de modo que os adolescentes foram informados sobre o problema de saúde que culminou na internação e no tratamento. Fato importante, devendo, pois, ser considerado, uma vez que a valorização dos direitos à informação e a participação das decisões tornam os usuários mais próximos das ações que possibilitam uma assistência qualificada em termos de eficácia e resulta em maior satisfação dos usuários adolescentes.

Os resultados mostram, de um modo geral, a aplicação das tecnologias leves em saúde no serviço, sendo a unidade onde se encontravam os adolescentes internados um local privilegiado neste aspecto, constituindo-se de ações humanitárias, ancoradas em relacionamentos interpessoais, de escuta, acolhimento e responsabilização. Alguns entraves, principalmente do acesso ao serviço, foram apontados. A porta de entrada mostrou-se mais acessível quando a demanda era referenciada por outros serviços terciários, o que suscita a reflexão sobre as formas de operacionalização do atendimento nos serviços de saúde, de modo a oferecer uma resposta adequada e imediata às necessidades e problemas trazidos por todos aqueles que procuram o serviço de atenção terciária.

Ao pensar no adolescente, em plena fase de maturação e busca de identidade que lhe possa servir como marca social, em situação de hospitalização, há necessidade de observar aspectos da relação, tais como: respeito à privacidade e a escuta do adolescente, estabelecendo um canal para o diálogo, a fim de que ele possa identificar seus limites e suas possibilidades, tornando-se sujeito ativo no processo de cuidado à saúde.

Destarte, é preciso repensar sobre as práticas de saúde realizadas, em especial, com os adolescentes hospitalizados, que carregam em si ansiedade, angústia, sofrimento e dor; buscar opções que possam intervir na melhoria da qualidade de atenção a esse grupo, de modo a superar situações que impedem a efetividade na produção do cuidado integral.

\section{REFERÊNCIAS}

1. Ferreira MA, Alvim NAT, Teixeira MLO, Veloso RC. Saberes de adolescentes: estilo de vida e cuidado à saúde. Texto Contexto Enferm. 2007 Abr-Jun; 16(2):217-24

2. Ministério da Ação Social, Justiça, Trabalho e Educação (BR). Lei no 8.069, de 13 de julho de 1990. Estatuto da Criança e do Adolescente. Brasília (DF): artigo 12, 1990.

3. Ministério da Saúde (BR), Secretaria de Atenção à Saúde. Saúde integral de adolescentes e jovens: orientações para a organização de serviços de saúde. Série A. Normas e Manuais Técnicos. Brasília (DF): MS; 2005.

4. Ministério da Saúde (BR), Secretaria de Atenção à Saúde. Política nacional de atenção integral à saúde do adolescentes e jovens. Versão Preliminar. Brasília (DF): MS; 2006.

5. Ramos FRS. Bases para uma re-significação do trabalho de enfermagem junto ao adolescente. In: Projeto Acolher. Adolescer: compreender, atuar, acolher. Brasília (DF): Associação Brasileira de Enfermagem (ABEn); 2001.p.11-8.

6. Henriques RLM, Pinheiro R. Responsabilidade pública e extensão universitária. In: Pinheiro $\mathrm{R}$, Mattos RA. Cuidar do cuidado: responsabilidade com a integralidade das ações de saúde. Rio de Janeiro (RJ): CEPESC: IMS/UERJ: Ed. ABRASCO; 2008.

7. Fontoura RT, Mayer CN. Uma breve reflexão sobre a integralidade. Rev Bras Enferm. 2006 Jul-Ago; 59(4):532-6. 
8. Silva K L, Sena RR. Integralidade do cuidado na saúde: indicações a partir da formação do enfermeiro. Rev Esc Enferm. USP. 2008 Mar; 42(1):48-56.

9. Minayo MCS, Souza ER, Santos NJ. Métodos, técnicas e relações em triangulação. In: Minayo MCS, Assis SG, Souza ER, organizadores. Avaliação por triangulação de métodos: abordagem de programas sociais. Rio de Janeiro (RJ): FIOCRUZ; 2005.

10. Flick U. Uma introdução à pesquisa qualitativa. $2^{a}$ ed. Porto Alegre (RS): Bookman; 2004.

11. Minayo MCS. O desafio do conhecimento: pesquisa qualitativa em saúde. $7^{\text {a }}$ ed. São Paulo (SP): Hucitec; 2000.

12. Ministério da Saúde (BR), Conselho Nacional de saúde, Comissão Nacional de Ética em Pesquisa. Resolução n 196 de 10 de outubro de 1996: diretrizes e normas regulamentadoras da pesquisa envolvendo seres humanos. Brasília (DF): MS; 1996.

13. Maas T. O Processo de transição do ser adolescente hospitalizado com doença crônica sob a ótica da Enfermagem [dissertação]. Curitiba (PR): Universidade Federal do Paraná. Programa de Pós-Graduação em Enfermagem; 2006.

14. Ministério da Saúde (BR), Conselho Nacional de saúde, Caderneta de saúde do adolescente [página na Internet]. Brasília (DF): MS; 2009 [acesso 2009 Jun 15]. Disponível em: http:// portal.saude.gov.br

15. Lima JC, Faveret AC, Grabois V. Planejamento participativo em organizações de saúde: o caso do Hospital Geral de Bonsucesso, Rio de Janeiro, Brasil. Cad Saúde Pública. 2006 Mar; 22(3):631-41.

16. Takemoto MLS, Silva EM. Acolhimento e transformações no processo de trabalho de enfermagem em unidades básicas de saúde de Campinas, São Paulo, Brasil. Cad Saúde Pública. 2007 Fev; 23(2):331-40.

17. Lima MADS, Ramos DD, Rosa RB, Nauderer TM, Davis R. Acesso e acolhimento em unidades de saúde na visão dos usuários. Acta Paul Enferm. 2007 Jan-Mar; 20(1):12-7.

18. Vieira MA, Lima RAG. Crianças e adolescentes com doença crônica: convivendo com mudanças. Rev Latino-am Enfermagem. 2002 Jul-Ago; 10(4):552-60.

19. Travassos C, Martins M. Uma revisão sobre os conceitos de acesso e utilização de serviços de saúde. Cad Saúde Pública. 2004; 20(Supl 2):S190-8.
20. Ministério da Saúde (BR), Secretaria de Assistência à Saúde, Departamento de Descentralização da Gestão da Assistência. Regionalização da Assistência à Saúde: aprofundando a descentralização com eqüidade no acesso. Norma Operacional da Assistência à Saúde - NOAS-SUS 01/02. Portaria MS/GM n ${ }^{\circ} 373$. de 27 fevereiro 2002 e regulamentação complementar. Brasília (DF): MS; 2002.

21. Ministério da Saúde (BR). Secretaria de Atenção à Saúde, Área de Saúde do Adolescente e do Jovem. Marco legal: saúde, um direito de adolescentes. Brasília (DF): MS; 2005.

22. Teixeira RR. Agenciamentos tecnosemiológicos e produção de subjetividade: contribuição para o debate sobre a trás- formação do sujeito na saúde. Cienc Saúde Colet. 2001; (6):49-61.

23. Schimith MD, Lima MADS. Acolhimento e vínculo em uma equipe do Programa Saúde da Família. Cad Saúde Pública. 2004 Nov-Dez; 20(6):1487-94.

24. Almeida IS, Rodrigues BMRD, Simões SMF. Desvelando o cotidiano do adolescente hospitalizado. Rev Bras Enferm. 2005 Mar-Abr; 58(2):147-51.

25. Gomes ILV. A criança hospitalizada, seus direitos e as relações interpessoais no cuidado e tratamento: caminhos e descaminhos [tese]. Rio de Janeiro (RJ): Universidade do Estado do Rio de Janeiro. Programa de Pós-Graduação em Saúde Coletiva; 2007.

26. Cecílio LCO, Merhy EE. A integralidade do cuidado como eixo da gestão hospitalar. In: Pinheiro R, Mattos R. Construção da integralidade: cotidiano, saberes e práticas em saúde. Rio de Janeiro (RJ): IMS-UERJ/Abrasco; 2003 Mar. p.197-210.

27. Merhy EE, Chakkour M, Stefano E, Stefano ME, Santos CM, Rodrigues RA, et al. Em busca de ferramentas analisadoras das tecnologias em saúde: a informação e o dia-a-dia de um serviço: interrogando e gerindo trabalho em saúde. In: Merhy EE, Onocko R, organizadores. Agir em saúde: um desafio para o publico. São Paulo (SP): Hucitec; 2002.

28. Pinheiro R, Mattos RA, organizadores. Construção da Integralidade: cotidiano, saberes e práticas em saúde. Rio de Janeiro (RJ): ABRASCO; 2003.

29. Pessini L, Bertachini L. Humanização e Cuidados Paliativos. São Paulo (SP): Loyola; 2004.

E-mail: veracioq@hotmail.com 